\title{
The privatisation of remembering practices in contemporary inpatient mental healthcare: going beyond Agnes's Jacket
}

\author{
Steven D. Brown ${ }^{1}$ (D) and Paula Reavey ${ }^{2}$ \\ ${ }^{1}$ Nottingham Business School, Nottingham Trent University, Nottingham, UK and ${ }^{2}$ Division of \\ Psychology, School of Applied Sciences, London South Bank University, London, UK \\ Corresponding author: Steven D. Brown, email: steven.brown@ntu.ac.uk
}

\begin{abstract}
In this paper, we consider changes to memorial practices for mental health service users during the asylum period of the mid-nineteenth up to the end of the twentieth century and into the twentyfirst century. The closing of large asylums in the UK has been largely welcomed by professionals and service-users alike, but their closure has led to a decrease in continuous and consistent care for those with enduring mental health challenges. Temporary and time-limited mental health services, largely dedicated to crisis management and risk reduction have failed to enable memory practices outside the therapy room. This is an unusual case of privatised memories being favoured over collective memorial activity. We argue that the collectivisation of service user memories, especially in institutions containing large numbers of long-stay patients, would benefit both staff and patients. The benefit would be in the development of awareness of how service users make sense of their past in relation to their present stay in hospital, how they might connect with others in similar positions and how they may connect with the world and others upon future release. This seems to us central to a project of recovery and yet is rarely practised in any mental health institution in the UK, despite being central to other forms of care provision, such as elderly and children's care services. We offer some suggestions on how collective models of memory in mental health might assist in this project of recovery and create greater visibility between past, present and future imaginings.
\end{abstract}

Keywords: collective memory; mental health; memory practices; Agnes Richter; patient memories

\section{Introduction}

In approximately 1895, Agnes Richter, an inmate from the Hubertusberg Psychiatric Institution near Dresden, Germany, meticulously inscribed into her asylum jacket what is thought to be an autobiographical narrative and set of difficult memories. This seamstress and long-term asylum inmate engaged in an intricate project to painstakingly record thoughts and feelings and commit them into the fabric of a durable memorial artefact. This unique piece of work has attracted a great deal of attention among historians and curators, partly because it is a rare example of rich symbolism and meaning in a group typically left in the shadows (see Hornstein 2012). Historically, asylum inmates' voices have often been silenced, the assumption being that the mad have nothing

(c) The Author(s), 2021. Published by Cambridge University Press. This is an Open Access article, distributed under the terms of the Creative Commons Attribution licence (http://creativecommons.org/licenses/by/4.0/), which permits unrestricted re-use, distribution and reproduction, provided the original article is properly cited. 
coherent to say; thus, the contents of recollections of madness are not considered for either their intelligibility or their meaning in some professional circles (Cromby et al 2013).

However, despite this tendency throughout history, there is a rich tradition of firstperson narratives of madness and incarceration. Some of the most well-known include those by John Perceval (see Bateson 1961) and Daniel Schreber (2000), both written in the nineteenth century, and more recently those of Susanna Kaysen (2000), Carol North (2013) and Barbara Taylor (2015). These have typically been in the form of published accounts, written when the author is in recovery, and often with the explicit aim of making sense of experiences that are unusual and sometimes frightening for the person concerned. In this sense, we might be tempted to see Agnes's meticulous inscriptions on her jacket as a tangible act of catharsis, enabling her to record and cope with her personal distress and institutional life through literally stitching her thoughts and establishing her voice in the very fabric she wore each day.

However, there is a significant barrier to understanding the memorial qualities of Agnes's Jacket. The text in which it is written is cryptic and defies exact translation (see Hornstein 2012). In addition, the legibility of the stitching has decayed over time. That it has survived at all is remarkable. In the 1920s, Hans Prinzhorn, the assistant director of the psychiatric clinic and art historian at the University of Heidelberg, happened to discover the jacket and preserve it, alongside thousands of other works of art created by asylum inmates institutionalised in Germany. His mission was to present a more meaningful picture of creation, innovation and meaning in the works of the mad and to bring to light the perceived relation between creativity, madness and the struggle for meaning (although many of Prinzhorn's artist-patients became victims of the subsequent Nazi regime - see English 2021). That work is now currently continued in a range of institutions that curate and exhibit the creative work of persons exploring their own mental health histories, such as The Bethlem Gallery and The Wellcome Trust, both in the UK.

While understanding the autobiographical arc of mental health experiences encoded within these art works is critical; what remains less explored is the relationship between the material practices of memorialisation and the enactment of 'madness' within inpatient settings. Agnes's Jacket is a corporeal diary of sorts. Sweat still marks the under arms and the countless and unnecessary needle pricks surrounding the inscription carry echoes of its owner's turmoil. But as a media for remembering, the jacket can also tell us something about how emergent memory practices were organised within a very particular institutional setting, how they intersected with the ongoing lived experiences of persons detained within them, and what kinds of prospects these may or may not have given rise to. Yet the obstacle here is that while practices such as art therapy are widely adopted within inpatient care, they tend to be viewed as discrete spaces for individual reflection and expression by patients, rather than as part of the broader work and responsibilities that these institutions have in relation to memory. In other words, artefacts like Agnes's Jacket are seen as purely personal expressions of a mental health journey, rather than as speaking to the broader role that practices of remembering have within inpatient mental healthcare. We argue that the way mental health institutions 'think' about memory, and the media through which remembering is enacted are partly constitutive of how mental health itself is conceptualised and treated.

This paper makes the case for exploring the problematic status of memories in contemporary psychiatric inpatient settings. We do this initially by describing existing memorial practices ranging from admission to therapeutic interventions. We argue that institutions remain resolutely focused on stabilising the mood and mental health of patients within the present, such that the default tendency is to operate as a 'system of forgetting' (see Brown and Reavey 2016). We then briefly discuss findings from a study of 'travelling 
memories' in psychiatric care, which identify several informal memorial practices negotiated at the ward level between patients and staff. While these practices occur across a range of media and appear to offer variable support for future recovery, we argue that they nevertheless tend to individualise the problem of living with a difficult past. While the now well-established problem within memory studies is the analytic tendency to absorb the personal within an often ill-defined notion of collective memory, psychiatric care offers a critical example of a reverse movement; where shared experience and joint histories are erased and memory firmly located within an individual life trajectory. We conclude with the seemingly counter-intuitive call for the collectivisation of memory within inpatient settings, based on the work conducted by mental health service user led organisations, and for mental healthcare institutions to take seriously their role as 'custodians of memory'.

\section{Patient memories: then and now}

At that time when Agnes Richter sewed words into her jacket, mental health care across much of Europe was dominated by large institutional spaces designated as asylums. While conditions were highly variable, even within individual countries, the common model was of a space of confinement, often located on the borders of urban populations, which would act as self-contained community of staff and patients. For instance, within Nottingham, a large industrial city in the East Midlands of the UK, a series of General Lunatic systems housing between 60 and 300 persons were built successively on the edges of the expanding city limits from 1812 onwards, until overcrowding required an entirely new site to be developed in the countryside several miles outside the city (Parr and Philo 1996). Such large asylums functioned in the manner that Goffman (1963) famously described as 'total institutions'. These are organised settings that establish a space and time outside of the normal patterns of everyday life, subject to very particular administrative procedures, which tend to shape the conduct and beliefs of persons on entry and may have significant barriers to exit. Memory takes on very particular forms in such an environment, where lived experiences of inmates are almost wholly subsumed by the institutional regime in which they dwell.

Yet, without denying the inhumanity of a system of incarceration that did seeming very little to alleviate the distress of patients, memorial practices within asylums were strikingly different to those found in contemporary psychiatric units. Clinical notes, for example, tended to be far more detailed and could provide extensive descriptions of daily events. Jonathan Andrews notes in the case of Glasgow Asylum in Scotland that during the middle part of the nineteenth century, case notes became far more systematically organised, with explicit directions given to the clinical staff charged with producing them, including directions to 'record the patient's mode of answering questions', his 'conversation', 'delusions', 'conduct', 'habits' and the 'effects of [the] visits of friends' (1998: 259). This could result in an extraordinary level of documentation - by contemporary standards at least - where clinicians would capture details in a literal fashion rather than merely those taken to be immediately relevant to treatment. Andrews reproduces the following example from George Reid, working at the Gartnavel Royal Asylum in Glasgow in the 1840s:

4 Oct 1844. On admission ... Wished to be informed why he was brought here and was anxious to know whether or not he was insane. Complained very much of the treatment he had received when in Glasgow. Knew every movement of his was watched ... 5 Oct 1844. Declares that he has not slept a moment during the night. Is up and dressed but looks very excited ... Says that Mr Stirling of Cadder has done him serious 
injury ... stated that the injury being great and Mr Stirling being a rich man ... the least he could give him was $£ 30,000$ or $£ 40,000$... that marriage would put an end to his troubles - that he had repeatedly written his views to Miss Stirling but has received no answer - that her father as a part of his system, intercepted his letters ... that Dr McFarlane \& Dr Moffat both saw him twice at least - that he is quite sane \& that both these medical men knew it - that he has been hurried here for the purpose of burying his wrongs in oblivion ... 6th Oct. 1844. Is today rather excited. Complains that he has not slept during the night wishes to have a man to attend him constantly, but more particularly to walk out with him as he has always been in the habit of taking violent exercise - Feels the want of it already \& knowing it will play the devil with his constitution - Talks in the same declamatory tone Mind teeming with fancies - This morning wrote the following letter to Dr McFarlane ... Dear Sir, it is perhaps owing to my not being so explicit as I ought to have been that I never intended this contest regarding the state of my mind should be closed free of a wife ... (cited in Andrews 1998: 278)

These meticulous records offer a contemporaneous narrative of the patient's experiences with little sifting or attempt to distinguish what may be delusional from what is 'real'. There is no attempt, for instance, to ascertain whether the patient's apparent persecution by $\mathrm{Mr}$ Stirling reflects an actual state of affairs or an unreliable recollection based on paranoid beliefs. According to Andrews, records of this kind contained little by way of judgement on the part of the clinician, with even remarks on clinical assessment being kept to a minimum. This meant that in the case of records of admissions, a narrative was recorded of the newly admitted patient's life history that enabled the contextualisation of their current distress in relation to recent life events.

This contextual approach - which is not dissimilar to what is now referred to as "clinical formulation' - became gradually overshadowed across the course of the twentieth century by a shift in focus towards diagnosis, where symptom patterns rather than life events per se were of principal interest (Cromby et al 2013). The role of the clinician changed from that of scribing the testimony provided by patients wholesale to identifying only those components judged relevant to establishing a diagnosis, which would then be extracted and massively abbreviated. This breaks apart the narrative arc of the testimony and downgrades the significance of life events and experiences to the status of the means of establishing 'symptoms'. It remains a common complaint among persons who have been detained in secure psychiatric care that clinicians are more interested in the question of 'what is wrong with you?' rather than 'what has happened to you?' (Dillon and May 2002). For instance, in one of our studies around sexuality and relationships within inpatient care, a patient participant expressed surprise that we were interested in talking about their life before being detained in hospital:

Res: How do you think the interview went?

Pat: Yeah. Yeah, I think the first bit was the hardest thing

Res: Yeah (laughs)

Pat: Like tell me about yourself, I've never really done that before (laughs) ...

I wasn't used to that, no-one's ever asked me.

(Res - Researcher; Pat - Patient) (cited in Brown et al 2014)

It might be thought that a major aspect of institutional mental healthcare would be a focus on memory and life experiences. In fact, very little of the time spent during inpatient care is formally allotted on reflecting on the past. There are a variety of reasons for this. Hospital care is normally seen across Europe as a resource-limited 'last resort'. 
The principal goal is to stabilise the patient so that they are no longer a 'risk to self, risk to others', such that they can be discharged to resume life within community-based mental health services. As such, remembering is seen as, at best, unhelpful, since it can lead to a rumination on past events rather than working on current mood and behaviour, or, at worst, as actively risky or threatening since it may elevate rather than de-escalate distress. The use of medication is omnipresent within inpatient care but is usually combined with other therapeutic interventions. These latter tend to be cognitive-behavioural approaches oriented towards present thoughts and actions rather than psychoanalytical approaches to understanding the significance of past events (the latter is typically only provided by private care practices in the UK, rather than as statutory provision through the National Health Service). Dialectical Behaviour Therapy (DBT), for instance, actively discourages rumination on the past and includes elements of mindfulness that are meant to facilitate 'being present' (Ivanoff and Marotta 2018). Resolving past difficulties is then a matter to be deferred to a much later point, if indeed at all.

Institutional spaces for reflecting on the past are also highly compartmentalised. Art therapy, for example, is widely used, but tends to be offered in discrete 'standalone' sessions. Reavey et al (2017) found in a study of a Child and Adolescent Mental Health inpatient service (CAMHS) that young people found it difficult to manage the emotions that arose during art therapy and mindfulness sessions, particular at the moments when they were expected to transition back into usual ward routines:

P: I went to (the mindfulness group), what (staff member) ran, but I just couldn't go to it. I wouldn't sit there or nothing, I was always fidgeting, I was always crying, it was just like really hard, especially like art therapy. That shouldn't be on the ward because that like really triggers people. That's one thing I would take off the flipping timetable ... it triggered loads of people. After (the mind-fulness group) finished, people would be in their rooms cutting themselves, they'd be in the bathroom; they wouldn't come out for dinner. They wouldn't even talk to no one. It's just such a bad idea (Patient cited in Reavey et al 2017: 215)

Young patients on the unit felt that the memories they recollected and the feelings these gave rise to were considered by staff as 'triggering' for other patients (i.e., provoking distress). Rather than be able to share their experiences, the lack of institutional procedures for linking what arose in art therapy and mindfulness with a broader, shared reflection on the past meant that the young people felt they had to manage their feelings in private, and sometimes did so in ways that were risky and harmful.

Such privacy and the accompanying privatisation of distress was just not possible in the old asylum system, where patients lived in dormitories on wards rather than individual bedrooms. The design of the space itself necessarily made remembering a visible part of day-to-day activities, rather than something which one endured in isolation. This could make for noisy spaces, replete with emotional interactions. Indeed, one of the 'selling points' for the introduction of the first generations of modern anti-psychotic medications was that they would render the wards silent by suppressing public displays of distress (Shen 1999). But these collective spaces also provided opportunities for patients to be engaged in day-to-day maintenance activities within the closed community, such as gardening, washing and cleaning. This also increased the opportunities for material practices of remembering, in the form of sewing, craftwork and group participation in sport and recreation. The focus on managing every aspect of the hospital environment for potential sources of risk is now so pervasive that it would be difficult to imagine how a patient in the present system could gain access to the materials that Agnes Richter possessed for the time required to fashion her jacket. The artefacts and material practices which previously 
helped to support remembering are now prohibited on the grounds of maintaining technical safety.

The physical environment of a modern inpatient has so little space for personalisation that it can appear that one of its functions is to remove all traces of past inhabitants. Katharine Lazenby, a peer-support worker and one of our fellow Directors in the Design in Mental Health Network, found that one of the notable features of her inpatient stay in St Anne's Hospital in Haringey was discovering an outside wall inscribed with the names of former patients (and possibly staff) (Figure 1).

The ability to literally carve one's name into the architecture of the building provides a material enactment of remembering, associating a difficult and distressing experience with the durability of the brickwork. This enactment simultaneously signifies to current patients that persons endure rather than disappear within the psychiatric system. As Katharine puts it 'they remind me of people being able to mark their territory and I find them so poignant. I think people need to have a sense that they are claiming their own identity' (cited in Reavey et al 2021). However, the wall no longer remains in the redeveloped 'New St Ann's' site which opened in 2020, with the old site having been sold for housing development. This is a common fate for many former asylum and psychiatric sites, with their grand Victorian construction and large internal spaces offering prime opportunities for private developers to create luxury apartment complexes. The 'afterlives' of asylums, as Moon et al (2015) describe them, is often in a form where little traces remain of either their previous functions or their relationships to the persons who were detained and who worked within them. Memory is literally displaced from the site.

This displacement is often coupled with a common tendency to remove archives from hospital spaces, even in cases where the space remains in use as a care or administrative setting. For example, St Andrews Healthcare previously maintained an extensive archival facility that contained records and artefacts dating back to its prior life as the Northampton General Asylum from 1838 onwards. In this archive, one might peruse artefacts as diverse as plans and arrangements for the secure transportation of patients by locomotive for a seaside holiday and the biography and clinical records of Violet Gibson, who was detained in the asylum after shooting a revolver at Benito Mussolini in Rome in 1926 (see Stoner-Saunders 2011). The archive was donated to local authorities in 2019 , and its likely fate is to be partly digitised, adding the dematerialisation of memory to displacement.

In summary, over a few decades, inpatient psychiatric spaces have been redesigned in terms of both their architecture and their methods of delivering care in ways that have problematised memory. There is no sense that remembering might then be practically and materially enacted in any way similar to that demonstrated by Agnes's Jacket. Patient memories no longer form part of the essential fabric of institutional experiences and care practices. Perhaps it is not surprising that the design of many modern healthcare facilities appears to follow some of the principles embedded in student accommodation and departure lounges, given that these are all examples of what Auge (2009) famously characterised as 'non-places' which give little purchase to notions of community and belonging. O'Doherty (2017) ironically notes that if Foucault was correct in identifying the prison as the archetype for the eighteenth and nineteenth century social organisation, then we must similarly understand the iconic role of the non-spaces of commerce and service provision within a contemporary 'loungification of society'. Our question then is how does memory nevertheless persist in such spaces? Where can we find the modern equivalent of Agnes's Jacket within inpatient settings? 

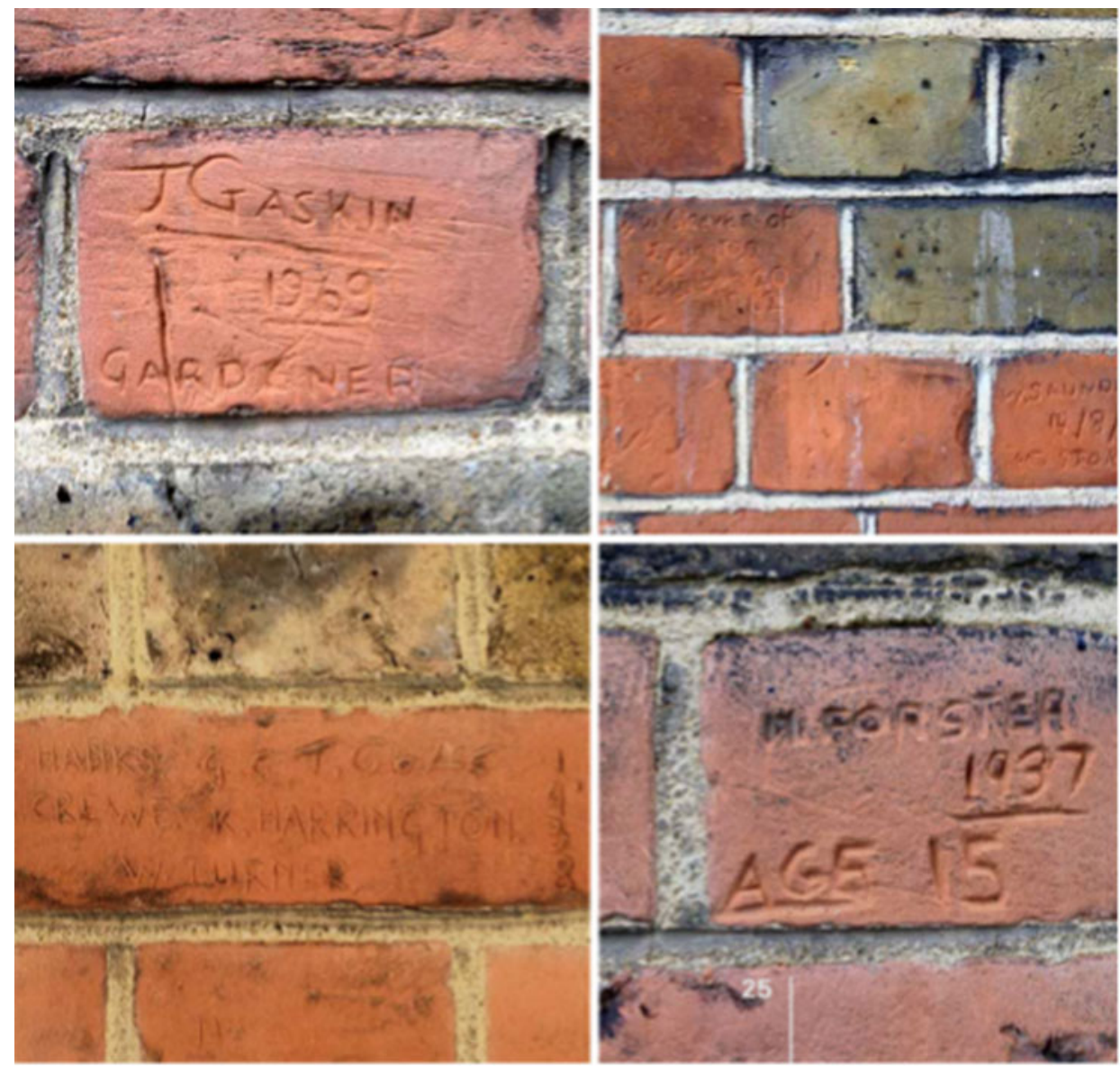

Figure I. Wall at St Anne's Hospital, Haringey (with permission, Katharine Lazenby).

\section{Travelling memories on the ward}

The unit where our research was conducted is the largest provider of non-NHS mental health inpatient services in the UK, focusing on 'specialist care', ranging from forensic secure care, complex dementia and services for older people. It also has one of the largest Child and Adolescent Mental Health (CAMHS) inpatient units in Europe. We initiated a project in 2017/2018 around memory with the unit in response to a perceived need. At the time of the project, a significant proportion of the patients within the unit had been cross-referred from the NHS across the country. This meant that many patients were arriving from geographically remote places (this kind of cross-referral in psychiatric services in the UK was due to be phased out before the COVID pandemic struck, but at the time of writing is still prevalent). Clinicians had noted that many patients who had arrived from distant points in the country chose to remain close to the unit after they were discharged, despite having no direct connection or actual experience of the surrounding city. We hypothesised that there was an issue around attachment to place, mediated through memory, and that patients' experiences during their time at the unit (which could vary from one or two to several years) were impacting upon this process. 
Our focus was on the female and male forensic pathways. These differ from other psychiatric services in that persons are detained without consent within a locked ward under a section 37 or 41 of the Mental Health Act (i.e., 'sectioned'), rather than section 2 or 3 used for short-term detentions. Section 37/41 detention is used by criminal courts in relation to an offence when it is believed that treatment within a hospital setting is more appropriate than time spent in prison. Persons detained under these sections have an 'index offence' and may have been transferred from the prison estate. Forensic psychiatric care is demarcated into 'high', 'medium' and 'low' security, ranging from a handful of units at the highest level to around 80 medium-secure units, and a large number of community-based housing environments at the lowest. Persons who enter the forensic psychiatric system do so for an unspecified period of time - decisions about which level of security they are to be detained within are made on the basis of clinical judgement and authorised by the UK Government Home Office.

Patients who are detained on section 37/41 are likely to move between a series of different settings before being discharged. This could be initially from either prison or a high secure unit to a medium-secure unit, followed by discharge to a low secure environment (sometimes there is a back and forth between these institutions). In any case, this movement across settings is likely to involve considerable geographical distance. The conditions of some section 41 detentions may also specify regional restrictions on where patients may be detained, typically at a distance from where an index offence has occurred. A likely consequence of this high level of mobility, protracted over several years, is that contact with family members and friends becomes complicated, increasing the difficulty patients' perceived of returning to the community where they formerly lived. In some cases, this may not be possible at all when the index offence concerns family members or events that have occurred within the local community.

Geographic mobility creates a tension within the delivery of care. Psychiatric services within the UK and constructed around a model of 'recovery' from crisis. Recovery is treated as a life-long process (modelled on the approach to physical chronic illness) which involves the person gradually taking responsibility for their own mental health to the point where they can resume living within the community (Cromby et al 2013). A key aspect of how recovery is theorised is the maintenance of relationships. In fact, a key point that emerges from the mental health service user/survivor movement, which originated the concept of recovery before its appropriation by the psychiatric system, is around the centrality of personal relationships in validating one's existence and experiences (Watson 2019). Complicating or weakening the ability of the patient to maintain such relationships during the period of secure care then pushes against one of the main aspects of the recovery model. From this perspective, the need to maintain memorial bonds with communities and place should then become even more critical.

Our starting point was the idea that the memorial work which patients would need to engage in would have to performed 'on the move' between numerous different settings. This would mean that patients would be denied access to the kinds of 'sites of memory' (lieux de memoire) whose importance is underscored by classic work within memory studies (Nora 1996). It might be considered that patients are in a position not unrelated to that experienced by migrants or asylum seekers, who must bring their memories of home with them as they are displaced across borders and countries. Astrid Erll's notion of 'travelling memory' is helpful here, with its focus on 'the incessant wandering of carriers, media, contents, forms and practices of memory, their continual "travels" and ongoing transformations through time and space, across social, linguistic and political borders' (2011: 11). Detention with the psychiatric system could indeed be compared, to some extent, with a kind of internal displacement, not least in terms of the kinds of institutional psychosocial management that both groups of persons are likely to 
encounter (see Mora-Gámez and Brown 2019). But the situation of patients differs from migrants in the key sense that the former does not have the resources and/or support provided by communities of fellow cultural members (e.g., sharing stories of 'home', recognition of one's common experiences). Patients have to do much of the work of managing their travelling memories on their own and with limited access to the kinds of 'media, contents, forms and practices' that Erll conceptualises.

The restriction on the resources available for remembering begins from the moment persons first enter the forensic psychiatric system. This can be in a very chaotic manner, following arrest for an offence or detention by the police or mental health crisis team under a section 135/136 order, which provides officials with a warrant to enter a person's home. Detention under these conditions can be highly disorienting, with the person potentially entirely unprepared to leave home. It is not uncommon to hear accounts of small amounts of possessions being rapidly placed into plastic rubbish bags for transport with the detainee, and we have ourselves seen such bags in patient's bedrooms on numerous occasions (see Figure 2). Given the importance of clothing, for instance, as potent artefacts for connecting memories to time and place (see Bendien et al 2010; Brown et al 2013), this inability to select what will 'travel with you' is problematic. Moreover, in many cases, these possessions can themselves become administratively displaced during transit, particularly when the patient is moved rapidly across several locations.

On admission to a secure unit, the patient will be consulted by a variety of clinical staff who will be responsible for developing an initial care plan. However, unlike that collected by George Reid and colleagues in the 1840s, this consultation will be focused almost entirely on extracting key details of the patient's condition rather than providing an opportunity for them to 'tell their story'. This is most likely to happen in the institutional context of a specialist Psychiatric Intensive Care Unit (PICU) ward, where initial stabilisation and triaging of the patient occurs. Staff on these wards are primarily concerned with calming the behaviour of newly admitted patients, who may be in a highly agitated state, through prescribing appropriate medication which may take some days to achieve functional strength. There are almost no opportunities for the patient to record their experiences at this critical point in their life - pens and paper, for example, are usually proscribed on the ward. Contact with persons on the outside world is also highly limited and may in any case be immediately complicated by the displacement of the patient to a geographically remote setting.

Almost all psychiatric wards in the UK are designed as single-sex settings with individual patient bedrooms (around 20 on a ward) and communal spaces. Patients are typically at liberty to spend time either in their bedrooms or on the ward space as they choose, outside of the time when there are structured activities (these tend to be limited). There has been much debate about the design of patient bedrooms and the extent to which these can function as 'home' for patients during their time in detention (National Association of Psychiatric Intensive Care and Low Secure Units 2017). The design specifications for these environments are heavily weighted in terms of embedding technical security' concerns around preventing absconding and the barricading of rooms, and most importantly removing any material surface that might enable self-harm, particularly through the removal of ligature points. In practice, this means that bedrooms typically have minimal fixtures, little by way of storage space, no doors on bathrooms and no toilet lids. Using the language of psychological 'affordances' originally developed by Gibson (1979), we might say that this is a space that clearly reminds patients that they are considered a danger to themselves and to the environment itself (see also Brown and Reavey 2015, 2019).

Patients have little ability to personalise their bedroom space. For example, if patients do have photographs or other images which they may wish to display, they then must find 


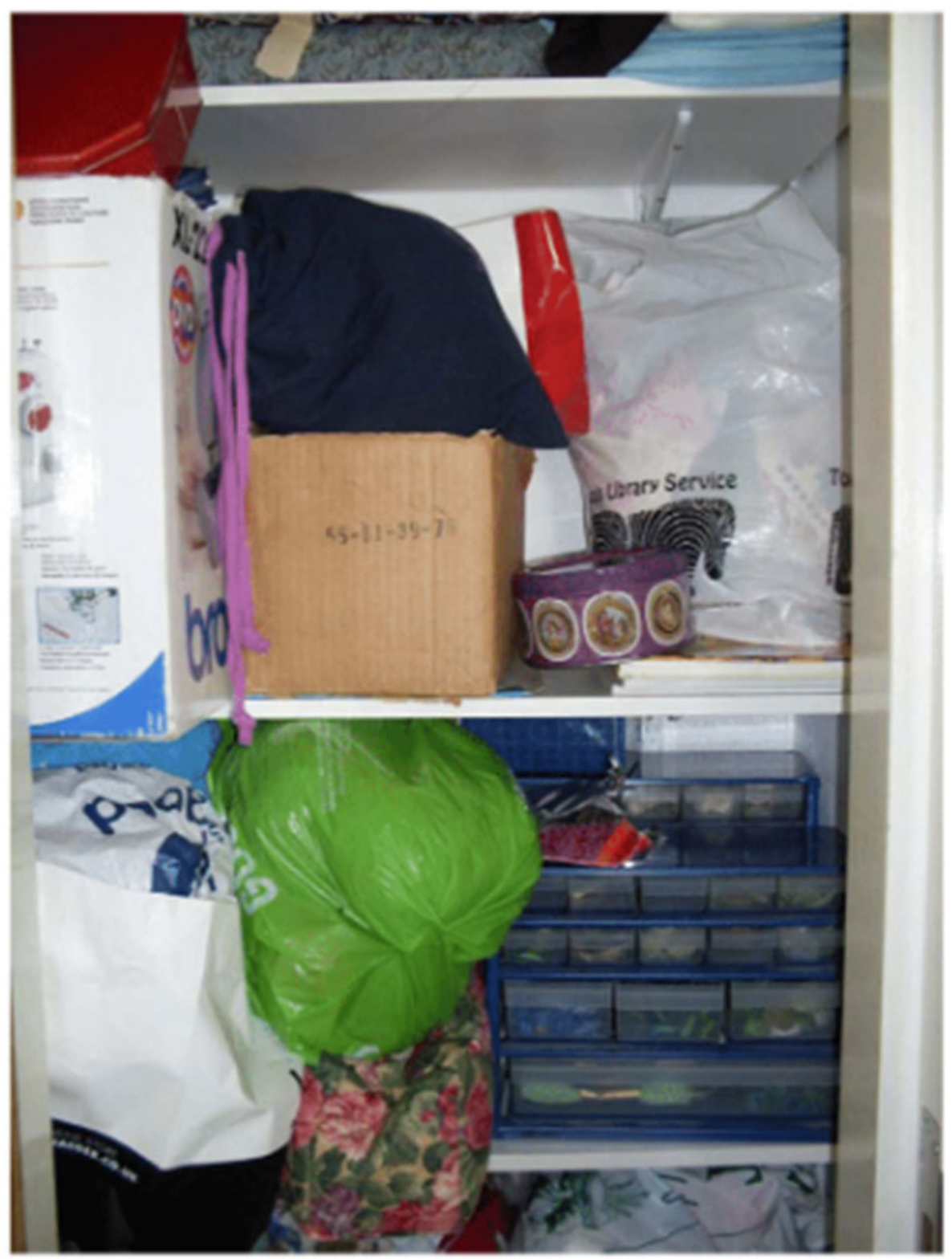

Figure 2. Patient bedroom in medium-secure unit.

a way to do so without using either pins or adhesive putty, which are banned from wards. But there may also be good reasons why patients do not wish to do so. Patients can be 'triggered' - that is, experience unwelcome recollections and emotions - by physical images from their past. In such cases, we found that patients tended to store photographs or letters within a space in their room where they would have to make a deliberate effort to view them. Where this was not possible, negotiation with ward staff sometimes allowed patients to store these possessions elsewhere on the ward and to request access at times when they either needed or felt able to engage with them again. However, a further 
challenge was around the media where photographs are now typically stored. Patients in secure care are usually neither able to readily access social media via the internet, nor allowed 'smart phones' with inbuilt storage for image libraries. This removes both the ability to view and to curate a series of images on which many contemporary remembering practices are based (Garde-Hanson et al 2009). Patients are furthermore not able to visually document their own experiences during detention (although we have in the past conducted studies where patients were allowed to do so for research purposes see Brown et al 2020a), which is a contributory factor to the sense many patients express that 'nothing ever happens' on the ward and that they have 'little sense of time passing'.

Other patients can, in principle, serve as resources and supports for remembering, but here again few patients choose to do so for good reason. It can be challenging for any person with a difficult and potentially traumatic past to narrate it to others, not least because putting their personal past in some kind of order may not necessarily make it easy to live with (see Brown and Reavey (2018) on the functional role of ambiguity in memory). For patients on a forensic pathway, their index offence typically looms large, since it is the principal reason for their current circumstances. Knowing someone else's history can be a kind of social currency in everyday ward life and there may be costs to entrusting one's story to another patient. Friendships between patients are also not well supported by staff in these spaces because of institutional concerns around these developing into personal relationships and intimacy between patients, with accompanying concerns around intimidation and predation (see Ravenhill et al 2020). As previously noted, staff are not charged with acting as witnesses to the stories of patients and in their day-to-day record keeping of patient experiences will tend to focus on mental health relevant signs and events. In other studies, we have observed staff maintaining daily records by cutting and pasting text exclusively focused on 'symptoms' where there are no concerns to report (see Brown and Reavey 2016). Again, this results in a privatisation of distress where the patient must conduct their memorial work on their own, as one patient describes in the following extract:

you don't know what's going to activate your mind during the day, the slightest em occurrence could em prompt you to come out with all sorts of thoughts when you're sitting on the ward ... the television to watch, music to listen to ... newspapers to read, then it does put you at ease and you're able to think more rationally about the past ... it gives you kinda time to think so it does give you time to reflect on the past

The absence of material or interactional media for the recording of experiences and histories creates a space where patients are to some extent stuck in the present - what we have elsewhere called 'present-ism' (Brown and Reavey 2015) - where thoughts of the past may emerge at any point. Using distractions such as watching television or listening to music may make such recollections more manageable. However, we have found in other work that disconnection between remembering and the present due in part to the lack of institutional concern with patient's stories can lead to sometimes idealised and 'frozen' conceptions of a past that are projected into an anticipated future. This may take the form of imagining that it is possible to return to a place or community that will be something like as it was, rather than having fundamentally changed. We have termed this relationship between frozen pasts and idealised futures 'spectral agency' in opposition to a capacity to dynamically reflect on the past in ways that give rise to plural possible futures (see Reavey et al 2019). In the present study, it was striking that a significant number of patients were anticipating a 'fresh start' upon discharge where they would seek a 'new normal life' in a new area, with different friendships and opportunities. Such an imagined future feels to be informed by the kind of approach taken in 
DBT, where escaping past patterns of behaviour, thinking and feeling are required as a condition for 'moving on' in life.

The question this raises for us is whether this kind of apparent settlement between the past and future - either in the form of a frozen past or a break with the past - is actually conducive of recovery in the longer term. To return to Agnes's Jacket, what seems important here is that it appears to contain a narrative of life experiences while at the same time offering multiple interpretative possibilities for what that narrative might be. We might say that it combines in a single media a conceptual object that invites the concerns and engagement of others with an ambiguous relationship to the past that can be read in numerous different ways. We have argued on multiple occasions for viewing ambivalence as a critical resource which allows tensions and contradictions in remembering to be held together in a way that may productively shape our orientation to the relevance of the past for the present (see Brown and Reavey 2015, 2018, 2020). So, once again, where do we find the modern equivalent of the jacket?

There are at least three potential practices we can identify in the current work. The first of these is the ways patients manage the limited number of possessions that they have with them in detention. Taking objects from a drawer or temporarily arranging them on display seems to be a strategy of 'unpacking' and 'repacking' the past. For a small period, patients can allow themselves to become immersed in their recollections in a way that does not risk being drawn into continuous rumination. This 'unpacking' practice, which may or may not be done in collaboration with ward staff, is a technique for making memories travel while also having the means for their containment. It also does a productive work of subjectification, in the sense that the unpacking is performed for someone, even if just for oneself (in other work, we have noted how female patients show their contents of their handbag to us as researchers as a form of this strategy).

The second is through the curation of music. As Pickering and Keightley (2015) have shown in some detail, the use of music as a medium for engaging in active remembering has considerable power. While patients may have limited ability to access the music they want to hear during their time in detention, merely invoking musical reference points can enable reflections on the past that might otherwise be absent, as in the following extract from a patient:

I've got Basshunter 'Now You're Gone', me and my ex used to listen to that a lot ... Oasis, Chasing Cars, all that type of stuff reminds me of home, Nickelback reminds me of my mum's erm husband ... Linkin Park, everyone like, Evanescence, everyone likes, Marshall Mathers ... I got my mum into that when I was young ... certain tracks remind me of stuff I've once done, it depends on the emotions I'm having at that time, it depends on what it's affected.

We clearly do not know much about the complexity of this patient's relationships to either 'home' or 'mum', but music here weaves a relationship that is every bit as powerful as the stitching on the jacket. Patients who can programme the soundscape of their bedroom with music are able to create a kind of temporary 'world within a world' where, in a relational sense, something of the past is brought to life within the present (see Brown et al 2020b).

Finally, as part of the current study we asked patients to maintain diaries over a period recording moments when they had recollected some experience of their life prior to detention. Despite the considerable logistical difficulties this posed for ward staff, the feedback we had from patients was that this was a pleasurable experience: 
I enjoyed filling out the diary erm I like writing about my experiences ... growing up and as an adult ... how different things have affected me ... remembering things in my past and how they've shaped my develop, growing up ... I realized how important my own family are to me

What this suggests is that the opportunity to work with traces of memory and to record them in material form need not be seen as antithetical to the delivery of care in forensic settings. In a sense, it is a practice that returns to notions of both mental health and memory that are far more fluid and less settled than those that currently drive the mental health system.

\section{Beyond Agnes's Jacket}

One of the notable features of memory studies is that it is typically concerned with scaffolding and representing the memorial practices of groups and communities whose relationship to the past has been problematised or subject to partial erasure - 'memories from below'. As part of this, our work has been concerned with groups such as survivors of childhood sexual abuse, parents of adoptive children, civil victims of conflict and elderly care residents, who all face significant memory challenges (Brown and Reavey 2015). It might be thought that researching the difficulties in managing the past among forensic mental health patients, who are perpetrators, but also in many cases victims, pushes too far in this direction. Our response is typically that persons who are detained in mental health services generally, and perhaps especially on forensic pathways, have experienced some of the worst social inequalities and welfare failings of any group in contemporary British society. In particular, they have often been unrecognised as communities who might require memorialisation, with their histories being literally bulldozed with the closure of the former asylums or else refurbished to feed the maw of neoliberal private property development.

Inpatient psychiatric care is then a rare instance where memory is increasingly more privatised than collectivised. The ever-expanding 'memory boom' which has seemingly reached nearly every aspect of contemporary social life (Hoskins 2014), to the point where the right to be forgotten is now increasingly the more problematic issue, simply has not reached mental health services. It is a curious anomaly that we probably know more about the lives and experiences of patients in the 1840s than we do of those in the 2020s. It has been left to the mental health service user/survivor community to call for memorialisation of lived experience and the difficult task of codifying the knowledge that arises from this. Organisations such as the Hearing Voices Network and the National Survivor User Network rather than the National Health Service are leading the work in the UK, preserving and collectivising lived experiences of distress. We echo their demand to support and expand the memorial practices of service users/survivors, and to see this work as fundamental to ensuring that history is celebrated not just in the former sites of memory, but across the communities and places where mental health is intertwined.

More specifically, we would call for institutions involved in mental health care to recognise that they have a role as custodians of memory as well as providers of care. If recovery depends on how a relationship to the past shapes imagined futures, then supporting memory practices during inpatient care needs to be seen as a statutory responsibility rather than as an 'add on' in the form of art therapy or mindfulness. Assisting patients in their collective work of caring for their own pasts (however difficult this may be) is every bit as important as the care that is delivered in the present. We have identified several examples of practices that might serve as modern versions of Agnes's Jacket, but 
doubtless there are many more. At the heart of all of them is the provision of media that allow patients to tell their stories without having them reduced to a series of symptoms, and which enable those inscribed stories to be engaged by others and accomplish a form of durability. There is clearly a role here for increased use of digital technologies within ward spaces and there is some evidence that the challenges of the COVID pandemic, where visits by relatives were necessarily done virtually rather than in person, have reduced the prior concerns regarding internet access in these spaces (see Reavey et al 2021).

But as in all issues around mental health, it is towards 'experts by experience' and service user/survivors that we need to turn to learn how memorial practices might be reshaped within inpatient care. The work done by the MadLove collective in rethinking psychiatric spaces as 'designer asylums', where the space is shaped and designed by experts by experience is a particular impressive instance of the kind of collective thinking that is required. Similarly, David Parkin's artwork 'Delusions of Grandeur', an installation imagining a dream patient bedroom and seclusion room filled with books, soft furnishings, sound and distractions shows how inpatient spaces might allow persons to inscribe something of their experience upon them. As Virginia Woolf writes in Orlando, 'Memory is the seamstress, and a capricious one at that. Memory runs her needle in and out, up and down, hither and thither. We know not what comes next, or what follows after'. These works help us to imagine the material form in which Agnes Richter's work might now be pursued.

Acknowledgements. The empirical research discussed in this article was funded by St Andrew's Healthcare. We would also like to thank Katharine Lazenby for permission to reproduce her photograph of St Anne's.

\section{References}

Andrews J (1998) Case notes, case histories, and the patient's experience of insanity at Gartnavel Royal Asylum, Glasgow, in the nineteenth century. Social History of Medicine 11, 255-281.

Auge M (2009) Non-Places: Introduction to an Anthropology of Supermodernity: An Introduction to Supermodernity. London: Verso

Bateson G (ed) (1961) Perceval's Narrative: A Patient's Account of His Psychosis 1830-1832. Stanford: Stanford University Press.

Bendien E, Brown SD and Reavey P (2010) Social remembering as an art of living: Analysis of a 'reminiscence museum'. In Domenech M and Schillmeier M (eds), New Technologies and Emerging Spaces of Care. Farnham: Ashgate, 149-167.

Brown SD and Reavey P (2015) Vital Memory and Affect: Living with a Difficult Past. London: Routledge.

Brown SD and Reavey P (2016) Institutional forgetting/Forgetting institutions: Space and memory in secure forensic psychiatric care. In Weik E and Walgenbach P (eds), Institutions Inc. London: Palgrave, 7-29.

Brown SD and Reavey P (2018) Contextualising autobiographical remembering: An expanded view of memory. In Mead M, Barnier A, Van Bergen P, Harris C and Sutton J (eds), Collaborative Remembering: How Remembering with Others Influences Memory. Oxford: Oxford University Press, 197-215.

Brown SD and Reavey P (2019) Vital spaces and mental health. BMJ: Medical Humanities 45(2), 131-140.

Brown SD and Reavey P (2020) Memory in the wild: Life space, setting specificity and ecologies of experience. In Wagoner B, Brescó de Luna I and Zadeh S (eds), Memory in the Wild: Niels Bohr Professorship Lectures in Culture Psychology. Charlotte, NC: Information Age.

Brown SD, Reavey P and Brookfield H (2013) Spectral objects: Material links to difficult pasts for adoptive parents. In Harvey P, Casella E, Evans G, Knox H, McLean C, Silva E, Thoburn N and Woodward K (eds), Objects and Materials: A Routledge Companion. London: Routledge, 173-182.

Brown SD, Reavey P, Kanyeredzi A and Batty R (2014) Transformations of self and sexuality: Psychologically modified experiences in the context of Forensic Mental health. Health 18(3), 240-260.

Brown SD, Kanyeredzi A, McGrath L, Reavey P and Tucker I (2020a) Reflections on a photo-production study: Practical, analytic and epistemic issues. In Reavey P (ed). A Handbook of Visual Methods in Psychology, 2nd edn. London: Routledge, 113-132. 
Brown SD, Kanyeredzi A, McGrath L, Reavey P and Tucker I (2020b) Organizing the sensory: Ear-work, panauralism and sonic agency on a forensic psychiatric unit. Human Relations 73(11), 1537-1562.

Cromby J, Harper D and Reavey P (2013) Psychology, Mental Health and Distress. Basingstoke: Palgrave.

Dillon J and May R (2002) Reclaiming experience. Clinical Psychology 17, 25-77.

English C (2021) The Gallery of Miracles and Madness: Insanity, Art and Hitler's First Mass-Murder Programme. London: William Collins.

Erll A (2011) Travelling memory. Parallax 17(4), 4-18.

Garde-Hanson J, Hoskins A and Reading A (2009) Save as...Digital memories. Basingstoke: Palgrave.

Gibson JJ (1979) The Theory of Affordances: The Ecological Approach to Visual Perception. Boston: Houghton Mifflin.

Goffman I (1963) Asylums: Essays on the Social Situation of Mental Patients and Other Inmates. Pelican: Harmondsworth.

Hornstein GA (2012) Agnes's Jacket: A Psychologists Search for the Meanings of Madness. Ross-on-Wye: PCCS Books.

Hoskins A (2014) Media and the closure of the memory boom. In Niemeyer K (ed). Contemporary Nostalgia and Media: Yearning for the Past, the Present, and the Future. Basingstoke: Palgrave Macmillan.

Ivanoff A and Marotta AL (2018) DBT in forensic settings. In Swales MA (ed). The Oxford Handbook of Dialetical Behaviour Therapy. Oxford: Oxford University Press.

Kaysen S (2000) Girl, Interrupted. London: Virago.

Moon G, Kearns R and Joseph A (2015) The Afterlives of the Psychiatric Asylum: Recycling Concepts, Sites and Memories. Basingstoke: Ashgate.

Mora-Gámez F and Brown SD (2019) The psychosocial management of human rights restitution: Reparation in post-conflict Colombia. Theory \& Psychology 29(4), 521-538.

National Association of Psychiatric Intensive Care and Low Secure Units (2017) Design Guidance for Psychiatric Intensive Care Units. Glasgow: NAPICU International Press.

Nora P (1996) Realms of Memory: The Construction of the French Past, Vol. 1. New York: Colombia University Press.

North C (2013) Welcome Silence: My Triumph over Schizophrenia. London: CSS Publishing.

O’Doherty D (2017) Reconstructing Organization: The Loungification of Society. Basingstoke: Palgrave.

Parr H and Philo C (1996) 'A Forbidding Fortress of Locks, Bars and Padded Cells': The Locational History of Mental Health Care in Nottingham. London: HGRG.

Pickering M and Keightley E (2015) Photography, Music and Memory: Pieces of the Past in Everyday Life. Basingstoke: Palgrave.

Ravenhill JP, Poole J, Brown SD and Reavey P (2020) Sexuality, risk and organisational misbehaviour in a secure mental healthcare facility in England. Culture, Health \& Sexuality 22(12), 1382-1397.

Reavey P, Poole J and Ougrin D (2017) The ward as emotional ecology: Adolescent experiences of managing emotional distress in inpatient settings. Health \& Place 46, 210-218.

Reavey P, Brown SD, Kanyeredzi A, McGrath L and Tucker I (2019) Agents and spectres: Life space on a medium secure forensic psychiatric unit. Social Science and Medicine 220, 273-282.

Reavey P, Brown SD, Ciarlo D and Lazenby K (2021) Design with People in Mind. Borders and Boundaries. London, UK: Design in Mental Health Network.

Schreber DP (2000) Memoirs of My Nervous Illness. New York: NYRB.

Shen WW (1999) A history of antipsychotic drug development. Comparative Psychiatry 40(6), 407-414.

Stoner-Saunders F (2011) The Woman Who Shot Mussolini. London: Faber \& Faber.

Taylor B (2015) The Last Asylum: A Memoir of Madness in Our Times. Harmondsworth: Penguin.

Watson J (2019) Drop the Disorder! Challenging the Culture of Psychiatric Diagnosis. Bristol: PCCS books.

Cite this article: Brown SD, Reavey P (2022). The privatisation of remembering practices in contemporary inpatient mental healthcare: going beyond Agnes's Jacket. Memory, Mind \& Media 1, e7, 1-15. https://doi.org/ 10.1017/mem.2021.8 